\title{
Visualization and Chemical Interpretation of Multi-Target Structure-Activity Relationships Using SOMPLS
}

\author{
Kiyoshi Hasegawa ${ }^{a}$, Kimito Funatsu ${ }^{b^{*}}$ \\ ${ }^{a}$ Chugai Pharmaceutical Company, Kamakura Research Laboratories, Kajiwara 200, Kamakura, \\ Kanagawa 247-8530, Japan \\ ${ }^{\mathrm{b}}$ The University of Tokyo, Department of Chemical System Engineering, Hongo 7-3-1, Bunkyo-ku, \\ Tokyo 113-8656, Japan
}

(Received June 17, 2011; Accepted July 8, 2011)

\begin{abstract}
In quantitative structure-activity relationships (QSAR), partial least squares (PLS) are of particular interest as a statistical method. Since successful applications of PLS to QSAR data set, PLS has evolved for coping with more demands associated with complex data structures. Especially, PLS variants focusing on visualization and chemical interpretation are highly desirable in modeling multi-target structure-activity relationships. In this paper, we employed the self-organized PLS (SOMPLS) approach to predict multiple inhibitory activities against three serine protease receptors (Thrombin, Trypsin and Factor Xa). Volsurf descriptors were used as chemical descriptors. From the SOMPLS analysis, we could catch rough trends about what chemical features are essential to each serine protease protein. Their chemical features could be successfully validated from X-ray crystal structures and the corresponding alignment residues.
\end{abstract}

Keywords: QSAR, PLS, SOMPLS, Serine protease inhibitors, VolSurf descriptors

*funatsu@chemsys.t.u-tokyo.ac.jp 


\section{Introduction}

It is crucial to establish the relationships between chemical structures and their biological activities in order to achieve the objective of performing better and fewer experiments. A quantitative description of the relationships is provided by the quantitative structure activity relationships (QSAR). If such a relationship can be derived from a structure-activity data, the model equation allows medicinal chemists to predict the biological activity of new molecule in advance. Partial least squares (PLS) are of particular interest because it can analyze data comprising numerous $X$ variables that have strongly collinear and noisy characteristics. It can simultaneously model multiple biological activities Y. Furthermore, it can provide us several prediction regions and diagnostic plots as the statistical measures [1]. Since successful applications of PLS to QSAR data set, PLS has evolved for coping with more demands associated with complex data structures [2]. Especially, PLS variants focusing on visualization and chemical interpretation are highly desirable in modeling multi-target structure-activity relationships.

Some studies for multi-target structure-activity (property) relationships have been reported in the literature [3, 4]. For example, Erhan et al. have used a collaborative filtering technique for building predictive models that link multiple biological targets to multiple ligands [3]. They have shown a multi-target (task) learning algorithm whose generalization performance is, on average, at least as good as the one of standard single-target learning. Varnek et al. have built predictive neural networks and PLS models for 11 types of tissue-air partition coefficients using multi-task learning [4]. They have demonstrated that multi-task learning technique is extremely useful in structure-property modeling on small and structurally diverse data sets when standard single-task learning is unable to produce any predictive model.

Recently, Melssen et al. have proposed bi-directional Kohonen (BDK) in modeling multi-task problems [5]. BDK is an extension of the Kohonen's self-organizing map [6-10]. It consists of two separate Kohonen maps: one for the input $\mathrm{X}$ and another map for the output Y. In a BDK network, the similarity between an output object $\mathrm{Y}$ and the units in the output map determines to a high extent the formation of the units in the input map, whereas the similarity between an input object $\mathrm{X}$ and the units in the input map drives dominantly the adaptations of the units in the output map. Hence, in a BDK network, two maps are updated in an alternating bi-directional way. BDK is open and transparent, allowing direct visualization and interpretation of the content of the underlying model.
The same group has expanded the BDK concept to its regression type. They have introduced a hyphenated regression technique that couples the transparency of BDK with the modeling power of PLS [11]. This technique is called as self-organized map PLS (SOMPLS). Analogous to the kernel based regression method such as support vector machine (SVM) [12], the kernel matrix serves as input descriptors to PLS. The kernel matrix is calculated by the similarity between the input descriptors and the weight vectors of the input map of BDK. Melssen et al. have applied SOMPLS to a calibration problem of six metabolites with unknown molecular concentrations [11].

In the previous study, we published first QSAR application using SOMPLS [13]. As a successive study, we reported second QSAR application on the same philosophy. Three serine protease inhibitors (Thrombin, Trypsin and Factor Xa) were used as data set [14, 15]. VolSurf descriptors were used as chemical descriptors [16]. They are converted from 3D molecular interaction field maps of chemical structure. From the SOMPLS analysis and the subsequent correlation maps, important chemical features to each serine protease were easily identified. Also, about each chemical structure, three protease inhibitory activities were predicted simultaneously thanks to the PLS framework. From the correlation maps, we could catch rough trends about what chemical features are essential to each serine protease protein. Their chemical features could be successfully validated from X-ray crystal structures and the corresponding alignment residues.

\section{Material and Methods}

\subsection{Data set}

In this study, the data set of three serine protease inhibitors (Thrombin, Trypsin and Factor Xa) was used. This data set has been throughly investigated as standard benchmark data $[14,15]$ and it is highly suitable for validation of our approach. The chemical structure is shown in Figure 1. Substituent positions are represented as $R_{1}$ and $R_{2}$. The 72 compounds and 16 compounds were used as the training and test sets as in the original literature [14]. The matrix consisting of 88 negative logarithm values of $\mathrm{K}_{\mathrm{i}}$ against 3 serine protease proteins was used as Y block descriptor. 
<smiles>[R1]N[C@@H](Cc1cccc(C(=N)N)c1)C([R2])=O</smiles>

Figure 1 Chemical structure of serine protease inhibitors.

\subsection{VolSurf descriptors}

In this study, we employed Volsurf software to calculate chemical descriptors of serine protease inhibitor. Volsurf descriptors are novel descriptors using the information embedded in 3D molecular interaction map [16]. Not all the information can be transferred from 3D to these new molecular descriptors, but practical examples do exist to show that the relevant information is indeed extracted $[16,17]$. Moreover, the descriptors have a clear chemical meaning and do not require structural alignments, and some of them can be projected back into the original 3D grid map to help interpretation $[16,17]$.

To each substituent $R_{1}$ and $R_{2}$, VolSurf descriptors were derived from 8 interaction volumes with DRY, O, and N1 probes in accordance with interaction energy thresholds. The interaction energy thresholds are -0.2 , $-0.5,-1.0,-2.0,-3.0,-4.0,-5.0$ and $-6.0 \quad(\mathrm{kcal} / \mathrm{mol})$, respectively. With regard to $\mathrm{O}$ probe, the value of the last interaction volume is missing, and the total number of VolSurf descriptors of each substituent amounted to be 23. Generally, if molecule has high hydrophobic character, Volsurf descriptors with DRY probe have the large interaction volumes. If molecule has many hydrogen-bonding acceptors, their descriptors with N1 probe have the large interaction volumes. Similarly, the descriptors with $\mathrm{O}$ probe have the large values if more hydrogen-bonding donors exist.

As for $\mathrm{R}_{1}$ substituent, $\mathrm{CH}_{3} \mathrm{NH}$ fragment was added to the substituent and the resulting $2 \mathrm{D}$ structure was transformed to the 3D structure by CORINA [18]. As for $\mathrm{R}_{2}$ substituent, $\mathrm{CH}_{3} \mathrm{CO}$ fragment was added, and the same procedure was applied. An example of the transformation for generating VolSurf descriptors is shown in Figure 2. CORINA can provide appropriate conformations for almost all molecules in a short period of time and then this conversion tool was used for generating $3 \mathrm{D}$ structure that is minimum requirement for VolSurf calculation. After all, the matrix consisting of 88 chemical structures and 46 VolSurf descriptors was used as X block descriptor.<smiles>CNS(=O)(=O)c1cccc2c(N(C)C)cccc12</smiles><smiles>[R2]#CN1CCN(S(C)(=O)=O)CC1</smiles>

Figure 2 Example of the transformation for generating VolSurf descriptors.

The calculation of VolSurf descriptors was carried out by Molecular Discovery Ltd. package [19]. The 3D structures of molecules are intact from CORINA default calculation and not optimized by any MM force field.

\subsection{SOMPLS}

The self-organized map PLS (SOMPLS) algorithm is briefly described in the following [11]. First, a bi-directional Kohonen (BDK) network is supervised. A BDK network consists of two coupled Kohonen self-organizing feature maps. The first map (referred to as Xmap) deals with the topology of the input data X. The second map (Ymap) having the same size as that of the Xmap embeds the multivariate structure present in the corresponding output space Y. In the first updating pass of a BDK network, only the weights of the units in the Xmap are adapted. This is repeated until all objects are presented once in a random order to the BDK network. The position of the winning unit corresponds to the location in the map for which the minimum in $\mathrm{S}_{\mathrm{ListX}}(\mathrm{i}, \mathrm{k})$ occurs. $\mathrm{S}_{\text {ListX }}(\mathrm{i}, \mathrm{k})$ is defined as equation (1).

$$
S_{\text {List } X}(i, k)=(1-\alpha(t)) S\left(X_{i}, X_{\text {mapk }}\right)+\alpha(t) S\left(Y_{i}, Y_{\text {mapk }}\right)
$$

Here $\mathrm{S}(\mathrm{X}, \mathrm{Xmap})$ denotes the Euclidean distances between an input object $X$ and all the unit weights in the Xmap. The same applies to S(Y, Ymap) but now for the associated output object $\mathrm{Y}$ and the units in the Ymap. The parameter $\alpha(\mathrm{t})$ regulates the relative weight between the similarities $\mathrm{S}(\mathrm{X}, \mathrm{Xmap})$ and $\mathrm{S}(\mathrm{Y}, \mathrm{Ymap})$. In the second updating pass, the Ymap units of the BDK network are adapted according to equation (2). 


$$
S_{\text {List } Y}(i, k)=\alpha(t) S\left(X_{i}, X_{\text {mapk }}\right)+(1-\alpha(t)) S\left(Y_{i}, Y_{\text {mapk }}\right)
$$

As a whole, the units in the Xmap and Ymap are updated in bi-directional manner according to equations (1) and (2).

Next, the similarity matrix obtained between the objects and the weight vectors of the converged BDK Xmap is weighted by a kernel function. This weighted similarity matrix will hereafter be referred to as the kernel matrix. The kernel function employed is the Pearson VII Universal Kernel (PUK). The PUK kernel function can be expressed as follows:

$$
K(i, j)=\frac{1}{\left[1+\left(\frac{2 \beta\left\|X_{i}-X_{\text {mapj }}\right\| \sqrt{2^{(1 / \omega)}-1}}{\sigma}\right)^{2}\right]^{\omega}}
$$

The core of the PUK is formed by the Euclidean distance between the input object $\mathrm{X}_{\mathrm{i}}$ and the BDK weight vector $\mathrm{X}_{\text {mapj. }}$ In equation (3), the parameter $\sigma$ determines the width (sharpness) of the Pearson VII function. The parameter $\omega$ controls the actual shape (tailing) of the function. $\beta$ in equation (3) is used as an internal normalization factor. This normalization assures that all distances between the input objects and the map weights are in the range [0-1]. The applicability, suitability, performance and robustness of PUK have been well investigated in the literature [20]. It was concluded that PUK has an equal or even stronger mapping power as compared to the standard kernel such as radial basis function kernel.

Finally, the relationship between the kernel matrix and biological activity is investigated by PLS. For each combination of the parameters $(\sigma$ and $\omega)$, the number of components of the PLS model is optimized by the 10 -fold cross-validation $(\mathrm{CV})$ based on the $\mathrm{Q}^{2}$ value. Concerning $\beta$, the constant value of 0.1 is used as the default setting.

The SOMPLS analysis was performed by the MATLAB [21] code developed in the Melssen's group [11]. In this code, PUK is default kernel and it is highly recommended for its usage. Owing to high speed of calculation and robustness, PUK was employed as the basis kernel in this study.

\section{Results and Discussion}

Before SOMPLS analysis, both of the biological activities and the VolSurf descriptors were mean-centered. The size of the BDK network was determined to be $6 * 6$ in order to achieve clear distinguished patterns among three Ymaps (Figure 3). The SOMPLS analysis yielded a ten-component PLS model. The squared values of correlation coefficients $\left(\mathrm{R}^{2}\right)$ for the training set are $0.771,0.743$ and 0.602 for Thrombin, Trypsin and Factor Xa, respectively. The corresponding $\mathrm{R}^{2}$ values for the test set are $0.465,0.634$ and 0.448 for Thrombin, Trypsin and Factor Xa, respectively. The $\sigma$ and $\varpi$ values in the PUK function were optimized to be 16 and 0.0625 by 10 -fold $\mathrm{CV}$, respectively. In a study of comparative molecular field analysis at $2 A^{\circ}$ resolution [14], the corresponding prediction abilities $\left(\mathrm{R}^{2}\right.$ for the test set) are $0.470,0.650$ and 0.384 for Thrombin, Trypsin and Factor Xa, respectively. It can be said that SOMPLS and CoMFA are comparable from their prediction performances.

For comparison, as single-task learning, PLS1 (single-property type) was applied to this data set. That is, PLS was applied to each target activity in turn. Same chemical descriptors and training/test sets as in SOMPLS were used. $\mathrm{R}^{2}$ for the training set are 0.713 , 0.725 and 0.684 for Thrombin, Trypsin and Factor Xa, respectively. $\mathrm{R}^{2}$ for the test set are $0.235,0.483$ and 0.302. Furthermore, as multi-task learning, PLS2 (multi-properties type) was applied. That is, PLS was applied to all three target activities. Same chemical descriptors and training/test sets as in SOMPLS were used. $\mathrm{R}^{2}$ for the training set are $0.480,0.590$ and 0.512 for Thrombin, Trypsin and Factor Xa, respectively. $\mathrm{R}^{2}$ for the test set are $0.133,0.268$ and 0.194 . In both cases, the statistical performance of SOMPLS is superior to those of PLS models. This result indicates that SOMPLS can give a balance model for satisfying internal and external predictions.

The BDK map for Y (Ymap) is shown in Figure 3. In Figure 3, the red and blue colors indicate active and inactive molecules, respectively. Among three serine proteases, Trypsin and Factor Xa have many overlaps between active regions. The similar Ymaps is actually reflected on the similar trends for inhibitory activities. (see Figure 4) 

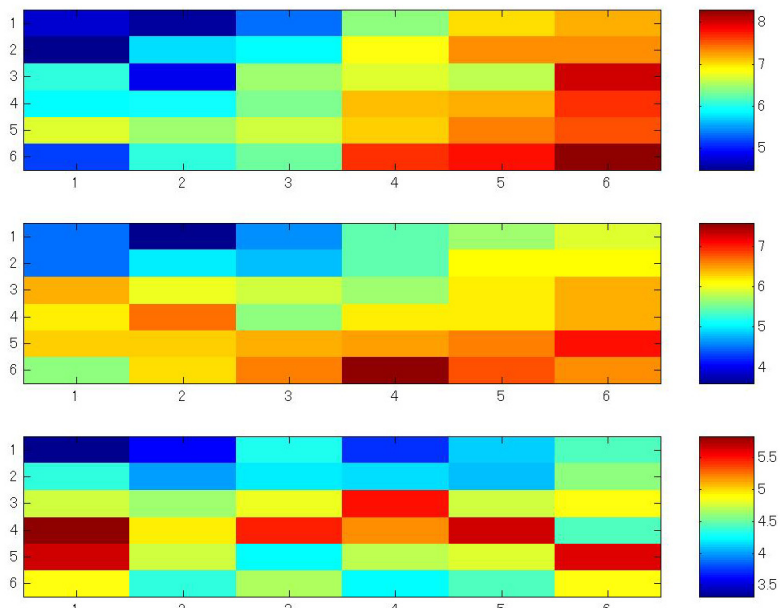

Figure 3 Ymap of three serine protease inhibitors (From top row, Thrombin, Trypsin and Factor Xa). X-axis and Y-axis form the 2D Ymap. Red and blue colors indicate active and inactive molecules,

The correlation maps between Ymap and 46 VolSurf descriptors are shown in Figure 4. The red, yellow, and blue colors indicate the positive, zero, and negative coefficient values, respectively. The $\mathrm{x}$-axis means six block descriptors derived from the combination of three types of VolSurf descriptors and two substituents. The y-axis means Thrombin, Trypsin and Factor Xa from the top row. From the correlation maps, we have derived three rough trends for high inhibitory activities. If the substituent $\mathrm{R}_{1}$ has high hydrophobic character, the inhibitory activities against Trypsin and Factor Xa would increase (Trend 1). If it has many hydrogen-bonding acceptors, all three inhibitory activities would increase (Trend 2). If the substituent $R_{2}$ has many hydrogen-bonding acceptors, the inhibitory activity against Trypsin would increase (Trend 3). In Figure 5, two examples for demonstrating trend 1 and 3 are shown.

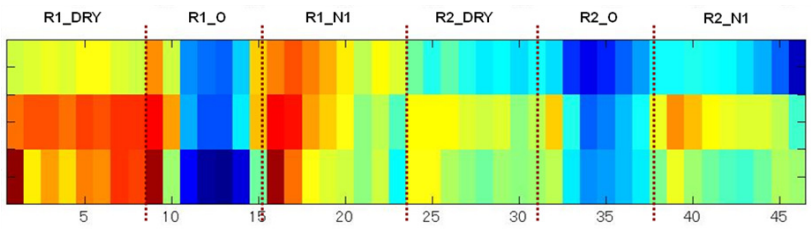

Figure 4 Correlation maps between Ymap and VolSurf descriptors. X-axis represents VolSurf descriptors derived from 8 interaction volumes with DRY, O, and N1 probes in accordance with interaction energy thresholds. Y-axis means Thrombin, Trypsin and Factor Xa from the top row. Red, yellow, and blue colors indicate the positive, zero, and negative coefficient values, respectively.

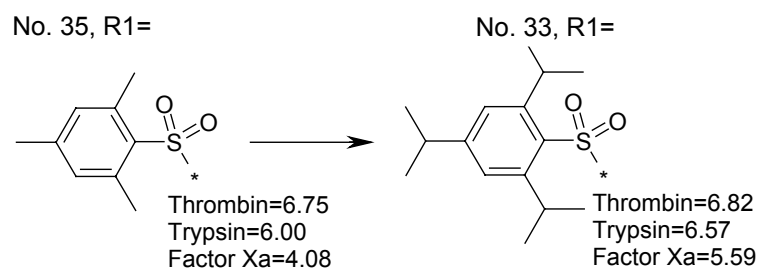

No. $24, \mathrm{R} 2=$

No. $9, \mathrm{R} 2=$
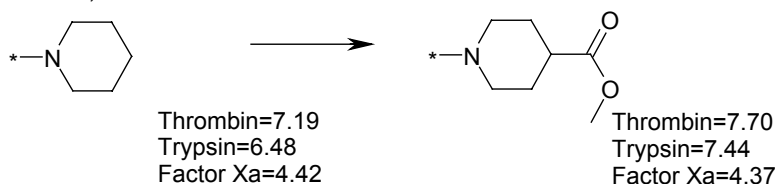

Figure 5 Two examples for demonstrating trend 1 and 3 .

According to three X-ray crystal structures (PDB codes: 1ETS of Thrombin, 1K1J of Trypsin, $1 \mathrm{HCG}$ of Factor $\mathrm{Xa}$ ) and the corresponding alignment residues, the nearest amino acid residues within $3.5 A^{8}$ from $\mathrm{R}_{1}$ are Glutamic acid 265, Serine 267, and Glutamic acid 267 in Thrombin, Trypsin and Factor Xa, respectively (Table 1).

Table 1: Nearest amino acid residues within $3.5 A^{\circ}$ from $\mathrm{R}_{1}$ or $\mathrm{R}_{2}$.

\begin{tabular}{|c|cccc|}
\hline Thrombin & & & & \\
\hline $\begin{array}{c}\text { Nearest AAs in } \\
\text { R1 } \\
\text { Nearest AAs in } \\
\text { R2 }\end{array}$ & W263 & G264 & E265 & G266 \\
\hline Trypsin & H79 & Y83 & W263 & G264 \\
\hline $\begin{array}{c}\text { Nearest AAs in } \\
\text { R1 } \\
\begin{array}{c}\text { Nearest AAs in } \\
\text { R2 }\end{array}\end{array}$ & W215 & G216 & S217 & G219 \\
\hline Factor Xa & H57 & - & W215 & G216 \\
\hline $\begin{array}{c}\text { Nearest AAs in } \\
\text { R1 } \\
\text { Nearest AAs in } \\
\text { R2 }\end{array}$ & W215 & G216 & E217 & G218 \\
\hline
\end{tabular}

The hydrophobicity of Serine is much higher than that of Glutamic acid. That indicates that molecule with hydrophobic substituent $R_{1}$ relatively shows high inhibitory activity against Trypsin. $\mathrm{R}_{1}$ substituent with hydrogen-bonding acceptor can make strong interaction with $\mathrm{NH}$ atom of each Glycine residue (Glycine 266 in Thrombin, Glycine 219 in Trypsin, Glycine 218 in Factor Xa, respectively). As for $\mathrm{R}_{2}$ substituent, due to deletion of one amino acid residue, $\mathrm{R}_{2}$ substituent with hydrogen-bonding acceptor can make interaction with NH atom of Glycine 216 residue limited only to Trypsin. All structural requirements about three serine protease inhibitors could be successfully validated from X-ray crystal structures and the corresponding alignment residues. 


\section{Conclusion}

In this paper, we employed the SOMPLS approach to predict multiple inhibitory activities against three serine protease receptors. VolSurf descriptors were used as chemical descriptors to make chemical interpretation feasible. From the SOMPLS analysis and the subsequent correlation maps, important chemical features to each serine protease were easily identified. Also, to each chemical structure, three protease inhibitory activities were predicted simultaneously thanks to the PLS framework. From the correlation maps, we could catch rough trends about what chemical features are essential to each serine protease protein. Their chemical features could be successfully validated from X-ray crystal structures and the corresponding alignment residues.

SOMPLS yields three important benefits. First, the BDK input and output maps allow a straightforward visualization and chemical interpretation of the regression model. Second, due to fact that in SOMPLS the number of similarity values per input object is equal to the number of units in the BDK input map, the size of the kernel matrix is reduced considerably as compared to the symmetrical kernel of SVM. Third, one BDK based kernel is required as input for the PLS algorithm. As compared to SVM, this single kernel character of SOMPLS might be advantageous with respect to the simplicity of the regression model.

SOMPLS would be a potential approach in chemogenomics from this study. The purpose of chemogenomics is to find any interesting inhibitors against an orphan target receptor whose function has not been understood and its inhibitor has not been known [22]. Schneider et al. have applied SOM for mapping different ligand classes and succesfully selected a promising library from many vendor catalogues [23]. SOMPLS is considered to be the advanced method from their approach. Therefore, SOMPLS could be used for de-orphanization of drug/targets. SOMPLS is an unique approach that makes data-mining feasible from visualization of structure-activity data biased to ligand-based view point.

\section{References}

[1] K. Hasegawa, K. Funatsu, Advanced PLS Techniques in Chemometrics and Their Applications to Molecular Design, pp 145-168 in Chemoinformatics and Advanced Machine Learning Perspectives: Complex
Computational Methods and Collaborative Techniques (Eds: H. Lodhi, Y. Yamanishi), IGI Global, 2011.

[2] K. Hasegawa, K. Funatsu, Curr.Comput.-Aided Drug Des., 2010, 6, 254-262.

[3] D. Erhan, P.-J. L'Heureux, S.Y. Yue, Y. Bengio, J.Chem.Inf.Model., 2006, 46, 626-635.

[4] A. Varnek, C. Gaudin, G. Marcou, I. Baskin, A.K. Pandey, I.V. Tetko, J.Chem.Inf.Model., 2009, 49, 133-144.

[5] W. Melssen, R. Wehrens, L. Buydens, Chemom.Intell.Lab.Syst., 2006, 83, 99-113.

[6] T. Kohonen, Self-Organization and Associative Memory, Springer Verlag, Berlin, 1988.

[7] L. Chen, J. Gasteiger, J.Am.Chem.Soc., 1997, 119, 4033-4042.

[8] M. Daszykowski, B. Walczak, D.L. Massart, Chemom.Intell.Lab.Syst., 2003, 65, 97-112.

[9] S. Matero, M. L.-Kakkonen, O. Korhonen, J. Ketolainen, R. Lappalainen, A. Poso, Chemom.Intell.Lab.Syst., 2006, 84, 134-141.

[10] D. Ballabio, V. Consonni, R. Todeschini, Chemom.Intell.Lab.Syst., 2009, 98, 115-122.

[11] W. Melssen, B. Ustun, L. Buydens, Chemom.Intell.Lab.Syst., 2007, 86, 102-120.

[12] K. Hasegawa, K. Fuantsu, Curr.Comput.-Aided Drug Des., 2010, 6, 24-36.

[13] K. Hasegawa, K. Funatsu, J.Comput.Aided Chem., 2010, 11, 56-61.

[14] M. Bohn, J. Sturzebecher, G. Klebe, J.Med.Chem., 1999, 42, 458-477.

[15] M. Arakawa, K. Hasegawa, K. Funatsu, Chemom.Intell.Lab.Syst., 2008, 92, 145-151.

[16] P. Crivori, G. Cruciani, P.-A. Carrupt, B. Testa, J.Med.Chem., 2000, 43, 2204 -2216.

[17] M. Koyama, K. Hasegawa, K. Funatsu, CBIJ, 2008, $8,85-95$.

[18] Molecular Networks:

http://www.molecular-networks.com/home

Henkestraße 9191052 Erlangen Germany.

[19] Molecular Discovery Ltd (MDL): http://www.moldiscovery.com/index.php

215 Marsh Road, 1st Floor HA5 5NE, Pinner, Middlesex UK.

[20] B. Ustun, W.J. Melssen, L.M.C. Buydens, Chemom.Intell.Lab.Syst., 2006, 81, 29-40.

[21] The MathWorks: http:http://www.mathworks.com/ 3 Apple Hill Drive Natick, MA 01760-2098, USA.

[22] D. Rognan, Mol.Inf., 2010, 29, 176-187.

[23] P. Schneider, Y. Tanrikulu, G. Schneider, Curr.Med.Chem., 2009, 16, 258-266. 
SOMPLS法によるマルチターゲット構造活性相関モデルの 図示化と化学的解釈に関する研究

\author{
長谷川 清 ${ }^{\mathrm{a}}$ 、船津 公人 $\mathrm{b}^{*}$ \\ a中外製薬株式会社・鎌倉研究所（干247-8530 神奈川県鎌倉市梶原200番地） \\ ${ }^{\mathrm{b}}$ 東京大学大学院工学系研究科（ $\bar{T} 113-8656$ 東京都文京区本郷7-3-1）
}

定量的構造活性相関(QSAR)では、部分最小 2 乗法(PLS)が統計手法として特に注目されている。 QSARへの成功例以来、PLSは複雑なデータ構造に関連するより複雑な要求を克服して進化して きた。その中で、特に、図示化と化学的解釈に特化したPLSの別法がマルチターゲット構造活性 研究では望まれてきた。本研究では、3つのセリンプロテアーゼレセプター(トロンビン、トリ プシン、ファクターXa)に対する阻害剤の活性予測のために、SOMPLSを適用した。VolSurf記述 子を化学記述子として使用した。SOMPLS解析の結果から、どのような化学構造的特徵がそれぞ れのセリンプロテアーゼタンパクの阻害に関連するかのラフなトレンドを見つけることができ た。X線結晶構造と対応するアミン酸から、これら化学構造的特徵の妥当性を検証することがで きた。

キーワード: QSAR、PLS、SOMPLS、セリンプロテアーゼ阻害剤、VolSurf記述子

\footnotetext{
*funatsu@chemsys.t.u-tokyo.ac.jp
} 